\title{
Diversidade Genética de Isolados de Phytophthora capsici de Diferentes Hospedeiros com Base em Marcadores RAPD Patogenicidade e Morfologia*
}

\author{
Edna Dora M. Newman Luz ${ }^{1 * *}$, Ademilde O. Cerqueira ${ }^{1}$, Fábio G. Faleiro ${ }^{3 * * *}$, Alfredo Dantas Neto ${ }^{2}$, \\ Kiyoshi Matsuoka ${ }^{4}$ \& José Raimundo B. Marques ${ }^{2}$ \\ ${ }^{1}$ Seção de Fitopatologia; ${ }^{2}$ Laboratório de Biotecnologia, Seção de Genética, CEPEC/CEPLAC, Cx. Postal 07, CEP 45600-000, \\ Itabuna, BA; ${ }^{3}$ Embrapa Cerrados, Cx. Postal 08223, CEP 73301-970, Planaltina, DF; ${ }^{2}$ Departamento de Fitopatologia, \\ Universidade Federal de Viçosa, CEP 36571-000, Viçosa, MG, e-mail: ednadora@ cepec.gov.br
}

(Aceito para publicação em 22/07/2003)

Autor para correspondência: Edna Dora M.N. Luz

LUZ, E.D.M.N., CERQUEIRA, A.O., FALEIRO, F.G., DANTAS NETO, A., MATSUOKA, K. \& MARQUES, J.R.B. Diversidade genética de isolados de Phytophthora capsici de diferentes hospedeiros com base em marcadores RAPD, patogenicidade e morfologia. Fitopatologia Brasileira 28:559-564 . 2003.

\section{RESUMO}

Phytophthora capsici é uma espécie onívora com vários hospedeiros cultivados na Bahia. Variações morfológicas ocorrem entre isolados de cacaueiro (Theobromae cacao), seringueira (Hevea brasiliensis) e pimenta-do-reino (Pipernigrum), todos classificados como $P$. capsici. Utilizaram-se marcadores RAPD e reações de patogenicidade para estudar a diversidade genética dentro desta espécie. Foram analisados 22 isolados sendo, oito de cacau, oito de seringueira, três de pimentão (Capsicum annuum) (dois antigos e um recente), um de abóbora (Cucurbita moschata), um de tomate (Lycopersicon esculentum) e um de pimenta-do-reino. Os isolados de pimentão, abóbora e tomate foram obtidos em Minas Gerais, o de pimenta-do-reino no Pará e, os demais, na Bahia e Espírito Santo. O DNA genômico de cada isolado foi extraído e amplificado utilizando-se oito primers decâmeros, os quais geraram 123 marcadores RAPD. Distâncias genéticas e análises de agrupamento permitiram a diferenciação de três grupos: o primeiro formado por isolados de cacaueiro, o segundo por sete dos oito isolados de seringueira e o terceiro por dois isolados de pimentão (antigos). Os isolados de tomate, pimenta-do-reino, pimentão (recente), o de abóbora e um de seringueira mostraram-se distantes geneticamente dos demais. Inoculações em frutos de cacau, seringueira, tomate e pimentão, com e sem ferimento, mostraram que o isolado de seringueira que não agrupou com os demais foi o menos virulento dos isolados testados, não causando lesões em frutos de seringueira sem ferimento. Frutos de pimentão só foram infetados por isolados de tomate e pimentão, enquanto os frutos de cacau foram infetados por todos os isolados testados. A manutenção de todos os grupos dentro de $P$. capsici é discutida.

Palavras-chave adicionais: Theobroma cacao, Hevea brasiliensis, Piper nigrum, Phytophthora, variabilidade.

\begin{abstract}
Genetic diversity of Phytophthora capsici isolates from different hosts based on RAPD markers, pathogenicity and morphology Phytophthora capsici is an omnivorous species and some of its hosts are cultivated in the state of Bahia. Morphological variations have been observed among isolates of $P$. capsici from rubber trees (Hevea brasiliensis), cacao (Theobromae cacao) and black pepper (Piper nigrum). RAPD markers and pathogenicity were used to study the genetic diversity within 22 isolates of the species. Eight isolates came from cacao, eight from rubber trees, three from green pepper (Capsicum annuum) (two collected earlier and one collected recently), and one each from black pepper, pumpkin (Cucurbita moschata) and tomato (Lycopersicon esculentum). Isolates from green pepper; pumpkin and tomato came from the State of Minas Gerais; the black pepper isolate was from the State of Pará; and the
\end{abstract}

\section{BSTRACT}

others from the States of Bahia and Espírito Santo. The genomic DNA of each isolate was extracted and amplified using eight decamer primers that generated 123 RAPD markers. Based on genetic distances and cluster analysis three groups were differentiated: one formed by cacao isolates, another by seven out of the eight rubber isolates and the third formed by the two earlier isolates of green pepper. Isolates of tomato, black pepper (recent), pumpkin, and one of rubber were genetically far from each other. Inoculations on fully developed but unripe fruits of cacao, rubber, tomato and green pepper, wounded or not, showed a rubber tree isolate that did not group with the others, infecting only wounded rubber pods. Only tomato and black pepper isolates infected green pepper fruits while all isolates tested infected cacao pods. The maintenance of all groups within $P$. capsici is discussed.
A espécie Phytophthora capsici Leonian (1922) emend. Tsao \& Alizadeh (1988), Tsao (1991); Mchau \& Coffey (1995) foi descrita pela primeira vez no Novo México, EUA, como

\footnotetext{
* Auxílio financeiro: CFC/ICCO/CEPLAC-BIOMOL e FUNDECAU

**Bolsista do CNPq

*** Bolsista do IBECAU
}

agente etiológico da requeima ou mela do pimentão (Capsicum annuиm L.) (Leonian, 1922). Durante algum tempo $P$. capsici foi considerada hospedeiro-específica, mas, com o assinalamento de novos hospedeiros, em outras regiões do mundo, mostrou-se polífaga e cosmopolita. Quarenta gêneros, de diferentes famílias de plantas, alguns com mais de uma espécie, 


\section{E.D.M.N. Luz et al.}

são hospedeiros de $P$. capsici incluídos entre as cucurbitáceas: melancia (Citrullus vulgaris Schrad.), melão (Cucumis melo L.), pepino (C. sativus L.), abóbora (Cucurbita moschata Duch.), abobrinha (Cucurbita pepo L.) e as solanáceas: pimentão (Capsicum annuum L.), pimenta-do-reino (Piper nigrum L.) e tomateiro (Licopersycon esculentum Mill.). Esta espécie encontra-se disseminada em quase todos os continentes com exceção da Oceania e causa diferentes enfermidades em seus hospedeiros que vão das requeimas ou mela e queda-anormal-das-folhas, à podridão de frutos, caules e raízes.

No Brasil, $P$. capsici foi assinalada pela primeira vez, em pimentão, por J.F. Amaral, em 1952 (Amaral, 1952), tendo aumentado muito o número de seus hospedeiros no país desde então. Na Bahia, entre os vários hospedeiros de importância econômica desta espécie, estão: o cacaueiro (Theobroma cacao L.), a seringueira [Hevea brasiliensis (Wild. Ex. A. Juss) Muell. Arg.], a pimenta-do-reino e o mamoeiro (Carica papaya L.), todas culturas de expressão na região sul e sudeste do Estado. No final dos anos 1970 e início da década de 1980, $P$. capsici foi responsável pela perda de inúmeras plantações de pimenta-do-reino no sul da Bahia, quase sempre localizadas próximas a plantios de cacaueiro e seringueira. Em seringueira, P. capsici, P. palmivora (Butler) Butler e P. citrophthora Leonian são responsáveis pelas doenças requeima, quedaanormal-das-folhas, podridão-dos-frutos, cancro estriado e cancro-do-painel. No cacaueiro, $P$. palmivora, $P$. citrophthora e $P$. capsici causam podridão-parda dos frutos, requeima das plântulas em viveiro, requeima das folhas e dos chupões no campo e cancro no tronco de plantas em produção. No final dos anos 1970 e início dos 1980, P. capsici predominou como agente da podridão-parda na Bahia e Espírito Santo (Campelo \& Luz, 1981). No entanto, no final da década de 1980, variações na distribuição populacional das espécies de Phytophthora que infetam o cacaueiro, foram observadas (Luz \& Silva, 2001), havendo tendência à predominância de $P$. citrophthora (dados não publicados).

Como a descrição de $P$. capsici (Leonian, 1922) abrangia apenas isolados de pimentão, e, alguns isolados de outros hospedeiros apresentavam características divergentes do tipo padrão, Tsao \& Alizadeh (1988) e Tsao (1991) redescreveramna para incluir os isolados de cacau, então classificados como P. palmivora (MF4), isolados de podridão-do-pé e murcha da pimenta-do-reino e de outros hospedeiros. Controvérsias surgiram com essa classificação dos isolados patogênicos ao cacau e outros hospedeiros tropicais em P. capsici. Pesquisadores do Havaí propuseram uma nova espécie, $P$. tropicalis Aragaki \& J.Y. Uchida, para classificar os isolados que produzissem clamidósporos, apresentassem esporângios alongados e que não fossem patogênicos ao pimentão (Uchida \& Aragaki, 1989; Aragaki \& Uchida, 2001). Posteriormente, Mchau \& Coffey (1995), considerando estudos isoenzimáticos com isolados de diversos hospedeiros neste e em trabalhos anteriores (Förster \& Coffey, 1991; Oudemans \& Coffey, 1991a,b), consolidaram a redescrição de Tsao \& Alizadeh (1988) e adicionaram-lhe dados isoenzimáticos e morfológicos complementares.

Procurando usar marcadores moleculares "Random Amplified Polymorphic DNA" (RAPD) como ferramenta auxiliar na classificação de isolados de Phytophthora da micoteca do CEPEC observou-se diversidade genética inter e intraespecífica, principalmente, entre isolados de P. capsici (Faleiro et al., 2003a). O presente trabalho teve por objetivo aprofundar os estudos sobre a variabilidade entre isolados de $P$. capsici de diferentes hospedeiros não apenas utilizando marcadores moleculares, como também alguns caracteres morfo-biométricos desses isolados e resultados de inoculações artificiais nos diferentes hospedeiros que originaram os isolados testados.

Vinte e dois isolados, sendo oito de cacaueiro, oito de seringueira, três de pimentão (dois antigos e um recente), um de abóbora, um de tomateiro, e um de pimenta-do-reino foram utilizados neste estudo (Tabela 1). Os isolados de cacaueiro foram obtidos de frutos, os de seringueira de folíolos e de painel e o de pimenta-do-reino do caule de planta infetada. Os isolados de pimentão, abóbora e tomate foram coletados em Minas Gerais e o de pimenta-do-reino, no Estado do Pará, cedido pelo Dr. Fernando Albuquerque (EMBRAPA/CPATU). Para extração do DNA genômico os isolados foram cultivados por sete dias em caldo de cenoura (caldo de $200 \mathrm{~g}$ de cenoura cozida e água completar 11 ) em BOD, à temperatura de $27^{\circ} \mathrm{C}( \pm$ $2{ }^{\circ} \mathrm{C}$ ), no escuro. A massa micelial de cada isolado foi seca ao vácuo e em seguida utilizada para a extração do DNA que foi realizada a partir de aproximadamente $250 \mathrm{mg}$ de massa micelial de cada isolado, utilizando-se o método do SDS com algumas modificações (Faleiro et al., 2003a,b). Após a extração, a quantidade e a pureza do DNA foram estimadas por espectrofotometria segundo Sambrook et al. (1989). Bandas de DNA genômico total, separadas por eletroforese em gel de agarose $0,8 \%$, foram usadas como indicadoras da integridade do DNA extraído.

Amostras de DNA $(10 \mathrm{ng} / \mu \mathrm{l})$ de cada isolado foram amplificadas pela técnica de RAPD, utilizando-se o mesmo procedimento descrito por Faleiro et al. (2003a, b). Foram utilizados os primers decâmeros OPH-18, OPN-16, OPN-4, OPA8, OPI-10, OPL-05, OPH-20 e OPM-15 (Operon Technologies).

Os marcadores RAPD gerados foram convertidos em uma matriz de dados binários, a partir da qual foram calculadas distâncias genéticas baseadas no complemento do coeficiente de similaridade (D) de Nei \& Li, utilizando-se o Programa Genes. A matriz de distâncias genéticas foi utilizada para realizar uma análise de agrupamento por meio de dendograma, utilizando o programa estatístico SPSS. O método do centróide foi utilizado como critério de agrupamento.

Para os estudos de caracterização morfo-patogênica, os isolados foram cultivados em corn meal ágar (CMA) e em cenoura-ágar (CA) (200 g de cenoura, $17 \mathrm{~g}$ de ágar e água para completar $1000 \mathrm{ml})$, em BOD, a $27{ }^{\circ} \mathrm{C}\left( \pm 1^{\circ} \mathrm{C}\right)$, no escuro. Após cinco dias, estudou-se a morfologia das culturas, usando-se um fundo preto para melhor visualização do formato das culturas. Simultaneamente, outras culturas dos mesmos isolados foram cultivadas em CA por sete dias, à mesma temperatura e sob luz fluorescente contínua, para formação de 
Diversidade genética de isolados Phytophthora capsici de diferentes hospedeiros...

TABELA 1 - Origem dos isolados de Phytophthora capsici utilizados no trabalho e seu grupo de compatibilidade

\begin{tabular}{|c|c|c|c|c|c|}
\hline $\mathrm{N}^{-\mathrm{r}}$ & $\begin{array}{l}\mathrm{N}^{\mathrm{a}} \text { de } \\
\text { reyist.ro }\end{array}$ & IInspedetro & Local de orìgen] & Ano de Isolamento & Grupo de Compatibilidade \\
\hline 1 & 183 & Seringueira & Vit lenga, RA & 1981 & A1 \\
\hline 2 & 185 & Setirugueira & ltuberí, BAA & 1984 & $A 1$ \\
\hline 3 & 51 & 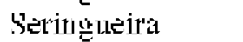 & ]'à.. Pirelli, liga, [3А & 1974 & $\wedge 1$ \\
\hline 4 & 152 & Seringueira & Faz. Mucambo, Lruçuca, BA & 1983 & $\Lambda 1$ \\
\hline 5 & 147 & 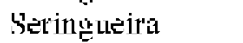 & ]'à. Bolandeira Una, $\mathbf{B} \wedge$ & 1983 & $\wedge 1$ \\
\hline 6 & 148 & Seringucira & Faz. Bolandeira, Una, Bへ & 1983 & $\Lambda 1$ \\
\hline 7 & 156 & Serimgucira & Faz. Firestone, Ituberá. $\mathrm{B} \Lambda$ & 1983 & $\Lambda 1$ \\
\hline 8 & 155 & Seringusira & Fay, Mueambo, Lruçuca. BA & 1983 & A 1 \\
\hline 9 & 1 & Choneiro & Гi⿱亠⿻ & 1977 & $\mathrm{~A} 2$ \\
\hline 10 & 64 & Cacaueiro & I:MARC, JrLlịuca, [3A & 1979 & $\Lambda 2$ \\
\hline 11 & 46 & Casaueiro & Linjlares, ES & 1980 & $\Lambda 2$ \\
\hline 12 & 134 & Cacauciro & Faz. Guanabara, Guaratinga. BA & 1981 & $\Lambda 1$ \\
\hline 13 & 241 & Cacauciro & ESMAI, Lna, BA & 1984 & $\Lambda 2$ \\
\hline 14 & 132 & Cacauciro & Faz. Boa Esperança, Lna, BA & 1981 & $\Lambda 2$ \\
\hline 15 & 138 & Cacalueiro & Fuz, Bøa Surte, Lna, BA & 1981 & $\mathrm{~A} 1$ \\
\hline 16 & 4 & Chchutiro & 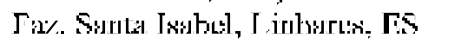 & 1977 & A2 \\
\hline 17 & 320 & Pimentâus & UJ]V, Vị̦osit: MGi & 1994 & $\Lambda 2$ \\
\hline 18 & 317 & l'imentāo & UFV- Tocantins, MG & 1974 & $\Lambda 1$ \\
\hline 19 & 321 & Abóbora & UFV, Viçosa, MG & 2001 & $?$ \\
\hline 20 & 316 & Pimentติด & UFV,Tocantins, MG & 1978 & A1 \\
\hline 21 & 43 & l'imenta do reino & EMER $\Lambda \perp \Lambda$, Belém, $\mathbf{I} \Lambda$ & 1978 & $\Lambda 1$ \\
\hline 22 & 319 & Tomale & UFV, Vicosa, MG & 1990 & 7 \\
\hline
\end{tabular}

? Grupo de compatibilidade não determinado

esporângios e liberação de zoósporos. No preparo das lâminas para exame microscópico, foram adicionados $10 \mathrm{ml}$ de água estéril a cada placa submetendo-as a choque térmico para descarga dos esporângios (Luz \& Silva, 2001). Calculou-se a concentração da suspensão de zoósporos obtida para cada isolado e mediu-se o comprimento do pedicelo, a largura e o comprimento de 50 esporângios de cada um dos isolados testados. Observou-se também se havia produção de clamidósporos.

Testes de patogenicidade de alguns isolados de diferentes hospedeiros a frutos verdoengos de cacaueiro, pimentão, tomateiro e seringueira foram realizados utilizando discos com $5 \mathrm{~mm}$ de diâmetro retirados de colônias com cinco dias de idade em cenoura-ágar. Os discos foram colocados na superfície de frutos, com e sem ferimento, recobertos com algodão umedecido e mantidos em câmara úmida. Os ferimentos foram feitos na superfície da casca dos frutos com o auxílio de um feixe de alfinetes entomológicos. Sete frutos, com e sem ferimento, de cada hospedeiro, foram inoculados com cada um dos isolados testados, a saber: dois isolados de cacaueiro (12 e 15), dois de seringueira (1 e 3), um de pimentão (17), um de tomateiro (22) e um de pimenta-do-reino (21). Em seringueira, 16 frutos, pertencentes aos clones da série IAN: 6742 (5), 6478 (5) e 2829 (6), resistentes ao mal-das-folhas [Microcyclus ulei (P. Henn.) v. Arx] e suscetíveis ao ataque de Phytophthora spp., foram inoculados com cada isolado, sendo feitos três pontos de inoculação, com ou sem ferimento, em cada fruto. Nos demais hospedeiros, as inoculações foram feitas em dois pontos lateralmente opostos. Igual número de frutos de cada hospedeiro foi usado como testemunha com e sem ferimento. Quatro dias após a inoculação, procedeu-se a avaliação, medindo-se o comprimento e a largura das lesões para cálculo do diâmetro médio das mesmas. Foram calculados os desvios padrões de todas as médias.

Os “primers" decâmeros utilizados geraram um total de 123 marcadores RAPD, com a média de 15,4 marcadores por "primer". As distâncias genéticas entre isolados obtidos do mesmo hospedeiro foram muito inferiores àquelas obtidas entre isolados de hospedeiros diferentes. Por exemplo, as distâncias genéticas entre isolados de seringueira variaram entre 0,013 a 0,164, e entre isolados obtidos do cacaueiro de 0,069 a 0,298. Já as distâncias genéticas entre isolados de seringueira e cacaueiro, variaram de 0,719 a 0,852. A maior distância genética, 0,885 , foi observada entre um isolado obtido de cacaueiro (14) e um de tomateiro (22). Os valores de distâncias genéticas entre isolados de diferentes hospedeiros observados neste trabalho foram inferiores, mas próximos, de valores de distâncias genéticas observadas entre isolados de diferentes espécies de Phytophthora. Faleiro et al. (2003a), utilizando a mesma ferramenta molecular e o mesmo índice, observaram distâncias genéticas de 0,881 a 0,982 entre isolados de $P$. capsici, $P$. palmivora e $P$. citrophthora obtidos do cacaueiro.

Com base em análises de agrupamento, utilizando-se um ponto de corte a $55 \%$ de distância genética relativa, foram obtidos três grupos: o primeiro formado por oito isolados de cacaueiro, o segundo por dois isolados de pimentão e o terceiro por sete isolados de seringueira (Figura 1). Os isolados de tomateiro, pimenta-do-reino, abóbora, pimentão (recente) e um de seringueira foram mais distantes geneticamente dos demais. Este resultado evidencia, a menor diversidade genética entre isolados obtidos do mesmo hospedeiro. A alta diversidade genética entre isolados de diferentes hospedeiros também foi 
Distância Genética Relativa (\%)

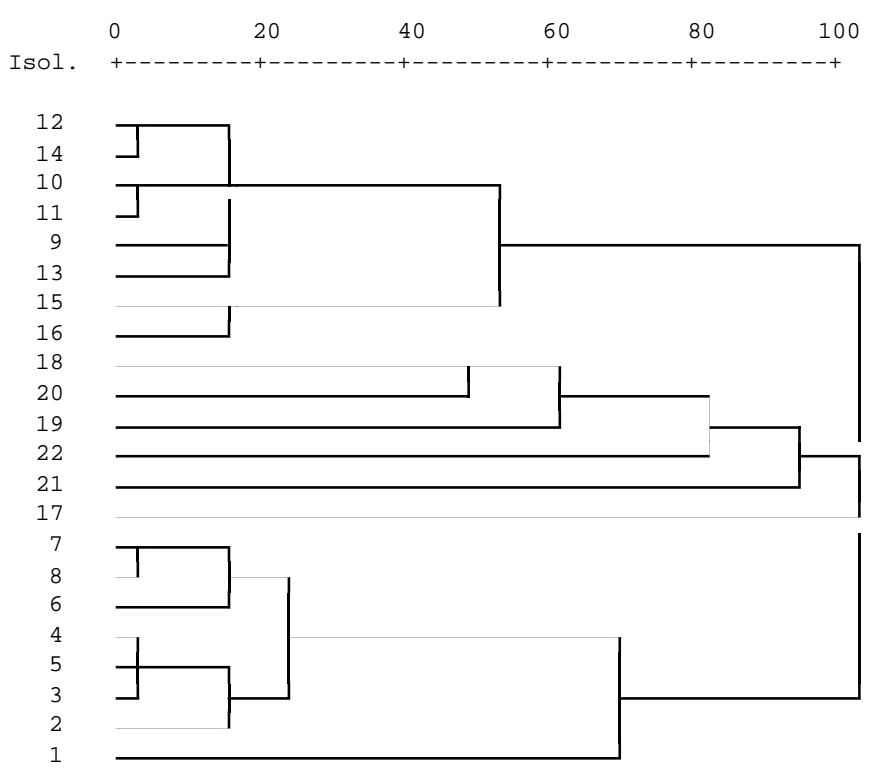

FIG. 1 - Análise de agrupamento de isolados de Phytophthora capsici baseada na matriz de distâncias genéticas, pelo método do centróide. Foram utilizados para o cálculo das distâncias genéticas 123 marcadores RAPD.

relatada por outros autores (Förster \& Coffey, 1991; Oudemans \& Coffey, 1991b; Mchau \& Coffey, 1995).

Os três isolados obtidos de pimentão não ficaram no mesmo grupo. Os isolados 18 e 20, antigos na coleção da UFV, foram mais semelhantes, entretanto o isolado 17, que foi coletado recentemente (1999) na mesma região, apresentou-se distante geneticamente dos demais. Alterações podem ter ocorrido nos isolados antigos ao longo do período de armazenamento, ou o patógeno sofreu variações genéticas em função do ambiente e do cultivo de outras variedades do hospedeiro.

As colônias dos isolados de cacaueiro e seringueira classificados como $P$. capsici, apresentaram-se petalóides ou estelares em CA e, predominantemente petalóides em CMA, segundo os padrões descritos por Cerqueira et al. (1999). Alguns isolados como 2, 3, 5 e 6, apresentaram micélio aéreo farináceo, com formação de pequenos grumos. Nos demais, o micélio aéreo era liso e mais denso apenas nas margens das pétalas ou estrelas. As culturas apresentaram diâmetro médio entre 7,3 e 8,8 cm após cinco dias de crescimento à temperatura de $27^{\circ} \mathrm{C}$. As variações nas medidas dos esporângios, relação comprimento/largura dos mesmos, profundidade da papila e comprimento do pedicelo, estavam todas dentro do padrão estabelecido para os isolados de $P$. capsici obtidos na região cacaueira da Bahia (Cerqueira et al., 1999). No entanto, no tocante a produção de zoósporos em culturas mantidas em $\mathrm{CA}$, a $27^{\circ} \mathrm{C}$, por sete dias, observou-se que os isolados $2,3,5$, 6 e 7 esporularam e liberaram zoósporos abundantemente, numa concentração média acima de $5 \times 10^{5}$ zoósporos $/ \mathrm{ml}$, enquanto, a produção dos isolados 1,4 e 8 foi dez vezes inferior à dos demais. Os isolados de cacaueiro produziram, em média, por cultura, de 0,2 a 1 x $10^{5}$ zoósporos $/ \mathrm{ml}$. As culturas mais esporulantes foram as do isolado 16 (10 zoósporos $/ \mathrm{ml})$, apresentando micélio aéreo menos denso que as demais e farináceo em algumas áreas. Os isolados de pimentão, abóbora e tomateiro apresentaram micélio aéreo muito denso e produziram em torno de $5 \times 10^{4}$ zoósporos $/ \mathrm{ml}$.

Nas inoculações em frutos de seringueira, sem ferimento, o isolado 1 não infetou os frutos de nenhum dos três clones (Tabela 2). Mesmo em frutos com ferimento, o isolado 1 foi menos agressivo que o isolado 3 aos três clones inoculados. $\mathrm{O}$ isolado 1 parece ser geneticamente mais divergente dos demais isolados obtidos da seringueira (Figura 1). Este isolado também não infetou frutos sem ferimentos de tomate e pimentão, e as lesões por ele causadas, em frutos com ferimento, nos hospedeiros testados, estavam entre as menores.

Frutos de tomate e de cacau sem ferimento foram infetados e lesionados por todos os isolados testados com exceção do isolado 1 que não infetou o tomateiro. Porém, frutos de pimentão, inoculados sem ferimento, só foram infetados por isolados de tomateiro (22) e pimentão (17). A patogenicidade do isolado de abóbora não foi testada.

Há variabilidade genética e patogênica entre os isolados de seringueira usados neste trabalho. Todos eles pertencem ao grupo de compatibilidade $\mathrm{A}_{1}$, que predomina entre isolados de $P$. capsici obtidos de seringueira, porém, os dois grupos ocorrem entre isolados de outras culturas que co-habitam no sul da Bahia (Câmpelo \& Luz, 1981). As variações observadas não podem ser atribuídas à distância geográfica, à data de isolamento ou ao órgão da planta afetada, pois estas variáveis estão presentes em outros dos isolados estudados. A hibridação natural pode ter contribuído para a variabilidade genética deste isolado.

Os isolados de cacaueiro usados neste trabalho foram obtidos na Bahia e no Espírito Santo e apresentaram baixas distâncias genéticas, entre si. Mchau \& Coffey (1995), observaram, com base em 18 sistemas enzimáticos, que os isolados de cacaueiro do Brasil, guardavam grande similaridade genética posicionando-se todos no mesmo grupo (CAP B), e sugeriram a existência de uma população clonal de $P$. capsici patogênico ao cacaueiro no Brasil. Os isolados de P. capsici obtidos no sul da Bahia e Espírito Santo, provenientes de seringueira, cacaueiro, pimenta-do-reino e eritrina (Erythrina glauca, Willd.) não produzem clamidósporos, característica de $P$. capsici sensu, mas apresentam várias divergências morfológicas com este tipo e entre si.

A diversidade de caracteres morfológicos, biométricos, moleculares e patológicos entre isolados de diferentes hospedeiros classificados como $P$. capsici existe e tem suscitado algumas polêmicas, principalmente quanto à acomodação dos isolados mais divergentes. Estes isolados não podem ser mantidos no antigo grupo MF4, pois, definitivamente eles não pertencem a $P$. palmivora que, apresenta, não só caracteres morfológicos divergentes - o tamanho do pedicelo é o principal deles, como é também geneticamente distinta dos isolados então classificados como P. capsici (Faleiro et al., $2003 \mathrm{a}, \mathrm{b}$ ). 
Diversidade genética de isolados Phytophthora capsici de diferentes hospedeiros...

TABELA 2 - Diâmetro médio das lesões (cm) obtidas cinco dias após a inoculação de diferentes isolados de Phytophthora capsici em frutos verdoengos de cacau (Theobroma cacao), tomate (Lycopersicon esculentum), pimentão (Capsicum annuum) e seringueira (Hevea brasiliensis) com ferimento $(\mathrm{C} / \mathrm{F})$ e sem ferimento $(\mathrm{S} / \mathrm{F})$

\begin{tabular}{|c|c|c|c|c|c|c|c|c|c|c|c|c|}
\hline \multirow{4}{*}{ ISOLADO } & \multicolumn{12}{|c|}{ 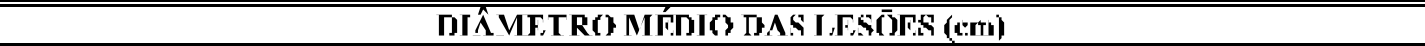 } \\
\hline & \multirow{2}{*}{\multicolumn{2}{|c|}{ CACAL }} & \multirow{2}{*}{\multicolumn{2}{|c|}{ PIMli.NIÄO }} & \multirow{2}{*}{\multicolumn{2}{|c|}{ TOMATE: }} & \multicolumn{6}{|c|}{ SERIVGLEIRA } \\
\hline & & & & & & & \multicolumn{2}{|c|}{$I A \cap 2829$} & \multicolumn{2}{|c|}{ I $\Lambda \wedge G 478$} & \multicolumn{2}{|c|}{ IA.V67742 } \\
\hline & $\mathbf{C} / \mathbf{F}$ & $\mathbf{S / F}$ & $\mathrm{C} / \mathrm{F}$ & $\mathbf{S} / \mathbf{F}$ & E:/F & $\mathbf{S / F}$ & $C / F$ & $\mathbf{S} / \mathbf{F}$ & $\mathbf{C} / \mathbf{F}$ & $\mathbf{S / F}$ & C/F & $\mathbf{S} / \mathbf{F}$ \\
\hline 1 (seringuleirs) & $\begin{array}{c}2,36 \\
(0,36)^{*}\end{array}$ & $\begin{array}{c}2,73 \\
(0,59)\end{array}$ & $\begin{array}{c}5,11 \\
2,00)\end{array}$ & 0,00 & $\begin{array}{c}5,10 \\
(3,68)\end{array}$ & 0,00 & $\begin{array}{c}3.25 \\
(0,75)\end{array}$ & 0.00 & $\begin{array}{c}1,30 \\
(1,35)\end{array}$ & 0,00 & $\begin{array}{c}3,00 \\
(0,94)\end{array}$ & 0,00 \\
\hline 3 (seringueita) & $\begin{array}{c}6,78 \\
\langle 0,57)\end{array}$ & $\begin{array}{c}6,83 \\
(0,54)\end{array}$ & $\begin{array}{l}10,50 \\
(1+, 60)\end{array}$ & 0,00 & $\begin{array}{c}7,75 \\
\langle 6: 47)\end{array}$ & $\begin{array}{c}5,17 \\
(1,29)\end{array}$ & $\begin{array}{c}5,71 \\
\langle(t: 17)\end{array}$ & $\begin{array}{c}5,24) \\
(0,87)\end{array}$ & $\begin{array}{c}6,07 \\
(0,15)\end{array}$ & $\begin{array}{l}2,47 \\
(1,27)\end{array}$ & $\begin{array}{c}<, 55 \\
(0,27)\end{array}$ & $\begin{array}{c}3.45 \\
(0.57)\end{array}$ \\
\hline 12 (cucau) & $\begin{array}{c}6.63 \\
\{0,64)\end{array}$ & $\begin{array}{c}4,45 \\
(0,41)\end{array}$ & $\begin{array}{r}8,00 \\
(0.54)\end{array}$ & 0,00 & $\begin{array}{c}7.58 \\
(0.88)\end{array}$ & $\begin{array}{c}7,33 \\
(2,66)\end{array}$ & $\begin{array}{c}9,25 \\
(1,24)\end{array}$ & $\begin{array}{c}2,90 \\
(0,45)\end{array}$ & $\begin{array}{c}3,97 \\
(2,98)\end{array}$ & $* * *$ & $\begin{array}{l}\angle, 20 \\
(1,27)\end{array}$ & $\begin{array}{c}2,00 \\
(0,50\}\end{array}$ \\
\hline 15 (cacalu) & $\begin{array}{c}6,40 \\
\{0,46\rangle\end{array}$ & $\begin{array}{c}6,53 \\
(0,29)\end{array}$ & $\begin{array}{c}x: 25 \\
(2.25)\end{array}$ & 0,000 & $\begin{array}{c}6,20 \\
(1,80)\end{array}$ & $\begin{array}{c}5,31) \\
(1,58)\end{array}$ & $\begin{array}{l}4.54 \\
(1,53)\end{array}$ & $\because$ & $\begin{array}{c}3,96 \\
(1,\{7\}\end{array}$ & $\begin{array}{c}2,17 \\
(0,44)\end{array}$ & $\begin{array}{c}2,50 \\
(1,10)\end{array}$ & 0,0 \\
\hline 17 (pimentì̀) & $\begin{array}{c}6,84 \\
(0,61)\end{array}$ & $\begin{array}{c}9,66 \\
(3,31)\end{array}$ & $\begin{array}{c}7.55 \\
(1,52)\end{array}$ & $\begin{array}{c}4,80 \\
(0,71)\end{array}$ & $\begin{array}{c}7.60 \\
(0.15)\end{array}$ & $\begin{array}{c}6,40 \\
(0,58)\end{array}$ & $\begin{array}{c}4.25 \\
(1.12)\end{array}$ & $* *$ & $\begin{array}{c}4,014 \\
(1,91)\end{array}$ & $\begin{array}{c}1.38 \\
(1,09)\end{array}$ & $\begin{array}{l}<, 80) \\
(1,16)\end{array}$ & $* *$ \\
\hline 21 (pimentu-ida-reinc) & $\begin{array}{c}6,77 \\
\{0.56\}\end{array}$ & $\begin{array}{c}4,92 \\
(2,98)\end{array}$ & $\begin{array}{c}6.25 \\
(0.53)\end{array}$ & 0,00 & $\begin{array}{c}6,25 \\
(1.19)\end{array}$ & $\begin{array}{c}5,04 \\
(1,88)\end{array}$ & $\begin{array}{c}2,8.5 \\
(0.38)\end{array}$ & is & $\begin{array}{c}3.55 \\
(1.02)\end{array}$ & $\begin{array}{c}1,75 \\
(0,35)\end{array}$ & $\begin{array}{c}2,15 \\
(0,78)\end{array}$ & 0,00 \\
\hline 22 (tomate) & $\begin{array}{c}6,60 \\
(0,61)\end{array}$ & $\begin{array}{c}7,65 \\
(1,42)\end{array}$ & $\begin{array}{c}5,64 \\
(0,38)\end{array}$ & $\begin{array}{c}5,63 \\
(0,83)\end{array}$ & $\begin{array}{c}(6,50 \\
(b, 47)\end{array}$ & $\begin{array}{c}5,05 \\
(1,50)\end{array}$ & $\begin{array}{c}2,95 \\
(0,41)\end{array}$ & 0,00 & $\begin{array}{c}3,50 \\
(1,(H))\end{array}$ & $\begin{array}{c}3,<2 \\
(0,65)\end{array}$ & $* *$ & 0,80 \\
\hline
\end{tabular}

Oudemans \& Coffey (1991b), com base nos caracteres moleculares e sistemas enzimáticos, concluíram pela existência de três grupos isoenzimáticos de $P$. capsici dentre os isolados testados (CAP1, CAP2 e CAP3). Utilizando-se desses dados e dos seus próprios estudos, Mchau \& Coffey (1995) redescreveram a espécie para acomodar as duas sub-populações por eles estabelecidas. No entanto, questiona-se a permanência de todos estes grupos dentro de um mesmo táxon, e propõe-se que novos e mais detalhados estudos genéticos e patológicos sejam conduzidos.

\section{REFERÊNCIAS BIBLIOGRÁFICAS}

AMARAL, J.F. do. Requeima-do-pimentão. O Biológico 18:160161. 1952.

ARAGAKY, M. \& UCHIDA, J.Y. Morphological distinctions between Phytophthora capsici and P. Tropicalis sp. nov. Mycologia 93:137-145. 2001.

CAMPÊLO, A.M.F.L. \& LUZ, E.D.M.N. Etiologia da podridão parda do cacaueiro nos Estados da Bahia e Espírito Santo, Brasil. Fitopatologia Brasileira 6:313-321. 1981.

CERQUEIRA, A.O., LUZ, E.D.M.N. \& ROCHA, C.S.S. Caracterização morfológica e biométrica de alguns isolados de Phytophthora spp. da micoteca do Centro de Pesquisas do Cacau. Fitopatologia Brasileira 24:114-119. 1999.

FALEIRO, F.G., LUZ, E.D.M.N., CERQUEIRA, A.O., ROCHA, C.S.S., DANTAS NETO, A., FLORES, A.B., BAHIA, R.C.S. \& FALEIRO, A.S.G. Diversidade genética de Phytophthora spp. isolados do cacaueiro com base em marcadores RAPD. Fitopatologia Brasileira 28. 2003a. (no prelo)
FALEIRO, F.G., LUZ, E.D.M.N., CERQUEIRA, A.O. \& ROCHA, C.S.S. Uso de marcadores RAPD como ferramenta auxiliar na classificação de isolados de Phytophthora spp. causadores da podridãoparda do cacaueiro no Brasil. Fitopatologia Brasileira 28. 2003b. (no prelo)

FÖRSTER, H. \& COFFEY, M.D. Approach to the taxonomy of Phytophthora using polymorphisms in mitochondrial and nuclear DNA. In: Lucas, J.A., Shattock, D.S., Shaw, D.S. \& Cooke, L.R. (Eds.) Phytophthora. Cambridge University Press. 1991. pp.164-83.

LEONIAN, L.H. Stem and fruit blight of peppers caused by Phytophthora capsici sp. nov. Phytopathology 12:401-408. 1922.

LUZ, E.D.M.N. \& SILVA, S.D.V.M. Podridão-parda dos frutos, cancro e outras doenças causadas por Phytophthora no cacaueiro. In: Luz, E.D.M.N., Santos, A.F., Matsuoka, K. \& Bezerra, J.L. (Eds.) Doenças causadas por Phytophthora no Brasil. Livraria Rural, Campinas. 2001. pp.175-265.

MCHAU, G.R.A. \& COFFEY, M.D. Evidence for the existence of two distinct subpopulations in Phytophthora capsici and a redescription of the species. Mycological Research 99:89-102. 1995.

OUDEMANS, P. \& COFFEY, M.D. Relationships between Phytophthora species:evidence from isozyme analysis. In: Lucas, J. A., Shattock, R. S., Shaw, D. S. \& Cooke, L. R. (Eds.) Phytophthora. Cambridge, Cambridge University Press. 1991a. pp.184-203.

OUDEMANS, P. \& COFFEY, M.D. A revised systematics of twelve papillate Phytophthora species based on isozyme analysis. Mycological Research 95:1025-1046. 1991b.

SAMBROOK, J., FRITSCH, E.F. \& MANIATIS, T. Molecular cloning: a laboratory manual. New York, Cold Spring Harbor Laboratory Press, Cold Spring Harbor, v.3. 1989.

TSAO, P.H. The identities, nomenclature and taxonomy of 


\section{E.D.M.N. Luz et al.}

Phytophthora isolates from black pepper. In: Y. R. Sarma \& T. Premkumor (Eds.) Diseases of Black Pepper. 1991. pp:185-211.

TSAO, P.H. \& ALIZADEH, A. Recent advances in the taxonomy and nomenclature of the so-called Phytophthora palmivora MF4 occurring on cocoa and other tropical crops. Proceedings $10^{\text {th }}$
International Cocoa Research Conference 17-23 May 1987, San Domingo, 1988. pp.441-445.

UCHIDA, J.Y. \& ARAGAKI, M. Comparison of pepper isolates of Phytophthora capsici from New Mexico to other solanaceous isolates. Phytopathology 79:1212. 1989. (abstract). 